\title{
THE OCCURRENCE OF C-MYC, P53 AND BCL-2 FAMILY PROTEINS IN THE EARLY PHASE OF DEVELOPMENT OF DUODENAL EPITHELIUM
}

\author{
Dana Kylarová, Jan Vrchovecký, Martin Holinka, Běla Erdösová
}

\author{
Department of Histology and Embryology, Faculty of Medicine, Palacký University, Olomouc, Czech Republic \\ e-mail:nepozit@tunw.upol.cz
}

Received: September 20, 2004

Keywords: Bcl-2 family/p53 family/Myc/Apoptosis/Embryo/Duodenum

In last few years, numerous groups of proteins participating in the regulation of cell proliferation, differentiation and death during ontogenesis have been described. In this study we compared the occurrence of Bcl-2, p53 and myc protein families with the level of proliferative activity and apoptosis during development of duodenal epithelium. Paraffin embedded tissues of eight human embryos and foetuses aged from the $6^{\text {th }}-18^{\text {th }}$ week of IUD were used. For the detection of apoptotic cells the TUNEL method was performed, the proliferative marker PCNA and all the proteins studied were detected by means of indirect three-step immunohistochemical method.

In the $6^{\text {th }}$ and $8^{\text {th }}$ week of intrauterine development we observed isolated TUNEL positive epithelial cells only and this was accompanied by the disperse presence of PCNA as well as by all the studied proteins: Bcl-2, Bax, Bcl-XL, c-myc, N-myc, p53, p63 and p73. In the early foetal period of duodenal development we registered changes in PCNA and TUNEL positivity in accordance with the constitution of the stem cell pool on base of villi, where more numerous Bcl-2 positive cells were also found. The separation of primitive crypts and villi was not accompanied by any differences in distribution of Bax, Bcl-XL, c-myc, N-myc, p63 and p73 proteins between those compartments: all the studied proteins showed dispersed character. P53 rapidly decreased in this period. In the $18^{\text {th }}$ week of intrauterine development the balance between proliferation in crypts and apoptosis of villi epithelium was well established and no p53 positive cells were found. In the presence of Bcl-2, Bax, Bcl-XL, p63 and p73 we did not find any dramatic changes. The myc proteins were restricted within the epithelium of the Lieberkühn crypts only.

\section{INTRODUCTION}

In this study we focused on the regulation of proliferation and apoptosis by Bcl-2, p53 and myc proteins during early phases of duodenal epithelium development. Differentiation of epithelial elements in human duodenum begins quite early: between the $5^{\text {th }}$ and $6^{\text {th }}$ week of intrauterine development and it depends on epithelial-mesenchyme interactions ${ }^{1}$. After beginning of differentiation of specific intestinal epithelium and formation of villi, the separation of two different compartments in epithelium follows. This is observable in adult intestine as well: tops of villi are represented by differentiated cells whereas proliferating stem cells remain on their base. The establishment of both compartments is proceeded in human foetuses during the first trimester ${ }^{2}$, although formation of tubular Lieberkühn crypts with typical Paneth cells at their bottom was described later, after the $14^{\text {th }}$ week of development.

In the normal adult intestinal mucosa, there is a well known balance between proliferation of stem cells in Lieberkühn crypt and programmed cell death via apoptosis of terminally differentiated enterocytes on the top of villi. Although regulation of cell proliferation and differentiation is established at the end of first trimester, the appearance of first apoptotic cells in the small intestine seems to be related to definitive organization of the intestinal crypt-villus axis similar to the state of adult intestine ${ }^{3}$. Rare apoptotic cells were also described in earlier stages of development, where their occurrence is connected to vacuolisation of epithelium during formation of intestinal villi ${ }^{4}$. Less information is available about apoptosis between the $8^{\text {th }}$ and $10^{\text {th }}$ week of intrauterine development, which is probably the critical period in establishment of the proliferating pool of stem cells in the duodenum.

Concerning the regulation of cell differentiation and death, besides locally specific signals, the involvement of several protein families both in adult and developing intestine has been described. There is evidence for the involvement of several proteins of the Bcl-2 family in intestinal development from the $10^{\text {th }}$ week of intrauterine development ${ }^{5}$. These proteins appear in adult intestine, as well. On the other hand, the role of p53 in intestine was studied especially in the adult intestine for its ability to block the cell cycle and induce apoptosis in cells exposed to DNA damaging stimuli ${ }^{6}$. However, this protein is also involved in control of cell differentiation, as was proved in cell cultures ${ }^{7}$ and several organs ${ }^{8}$. This function of $\mathrm{p} 53$ seems to be partially influenced by the splicing variants of the rest of the p53 family proteins p63 and p 73 in adult tissues ${ }^{9}$. The transactivating function of $\mathrm{p} 53$ is also involved in the control of bcl-2 gene transcription ${ }^{10}$ : $\mathrm{p} 53$ 
enhances transcription of the pro-apoptotic bax gene and inhibits transcription of its anti-apoptotic relation gene Bcl-2. Myc proteins being able to control cell cycle, differentiation and apoptosis were found to be necessary for normal development on knock-out animal models: mice lacking either c-myc or N-myc die before the $12^{\text {th }}$ day of intrauterine development and the occurrence of those proteins has been described in several parts of gastrointestinal tract ${ }^{11}$.

\section{MATERIAL AND METHODS}

In our study we examined the duodenum of 8 embryos and foetuses aged from 6 to 18 weeks of i.u.d. All the samples were fixed in buffered formol or methacarn and embedded in paraffin in a routine method. Paraffin sections $6 \mu \mathrm{m}$ thick were used both for labelling of apoptotic cells via the TUNEL method and immunohistochemical detection of all the proteins under study: Bcl-2, Bcl-XL, BAX, c-myc, N-myc, p53, p63, p73 and proliferative marker PCNA.

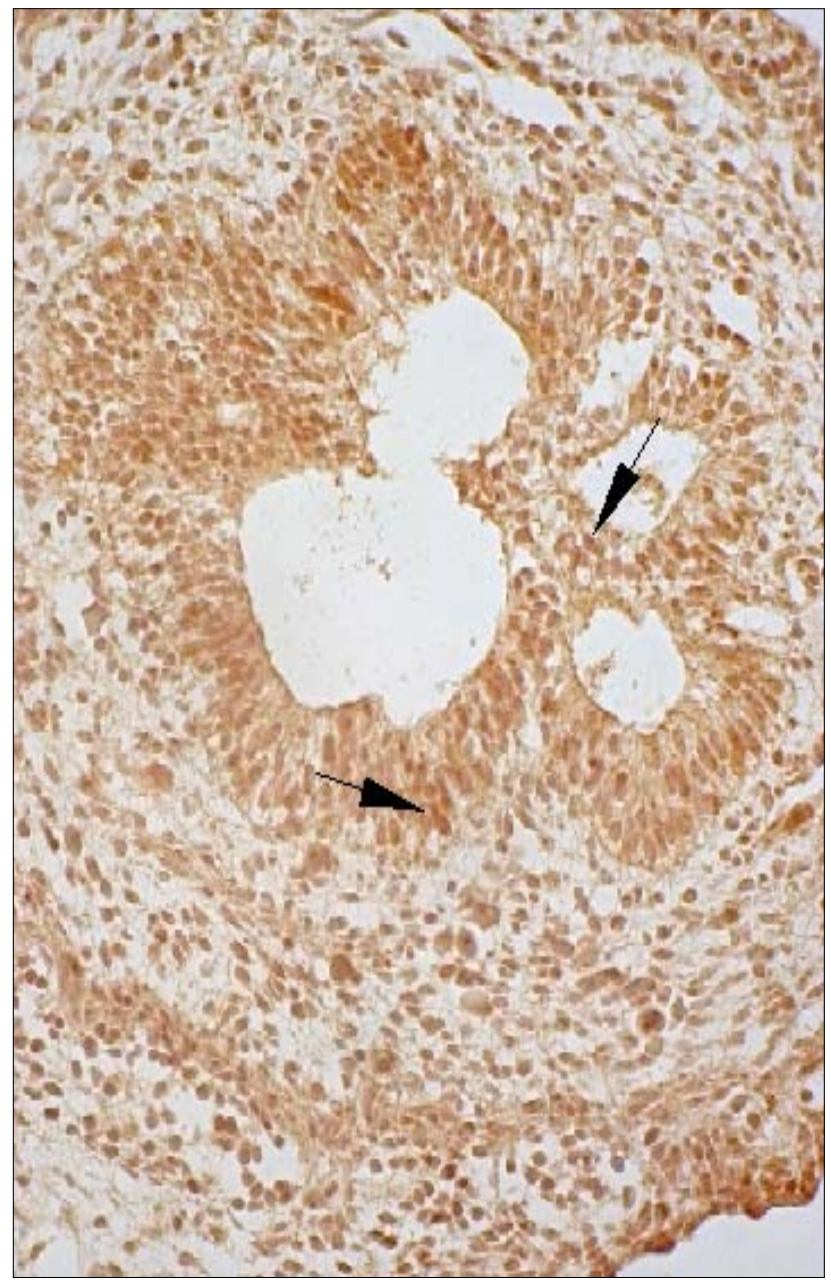

Fig. 1. c-myc positive cells (arrows) in duodenum of the 6-week-old embryo. Magn. 400x
For the TUNEL method "In Situ Cell Death Detection Kit" (Roche) was used, vizualisation was performed by alkaline phosphatase-NBT/BCIP reaction. Indirect standard three-step immunohistochemical method using monoclonal and polyclonal antibodies was applied for the detection of PCNA, p-53 and Bcl-2 family proteins. For the immunohistochemical assay we used the following primary antibodies: monoclonal anti Bcl-2 (Biogenex), Bax (Immunotech), c-myc, N-myc (Santa Cruz Biotechnology) and PC-10, DO-7 and p-73 $\alpha 1.1$ (all made by MOÚ) and rabbit polyclonal: p-63 $\alpha$ (MOÚ). Either horseradish peroxidase-DAB or alkaline phosphataseNBT/BCIP reactions were used for vizualisation and hematoxylin or nuclear red were additionally used for counterstaining. Additionally, the sequential double staining technique was applied for several samples using the vizualisation techniques described above. We evaluated changes in protein levels in differentiating epithelium of duodenum. The occurrence of positive cells was evaluated semiquantitatively: 0 - no positive cells, + isolated positive cells, ++ regular positivity in groups of cells, +++ massive positivity.

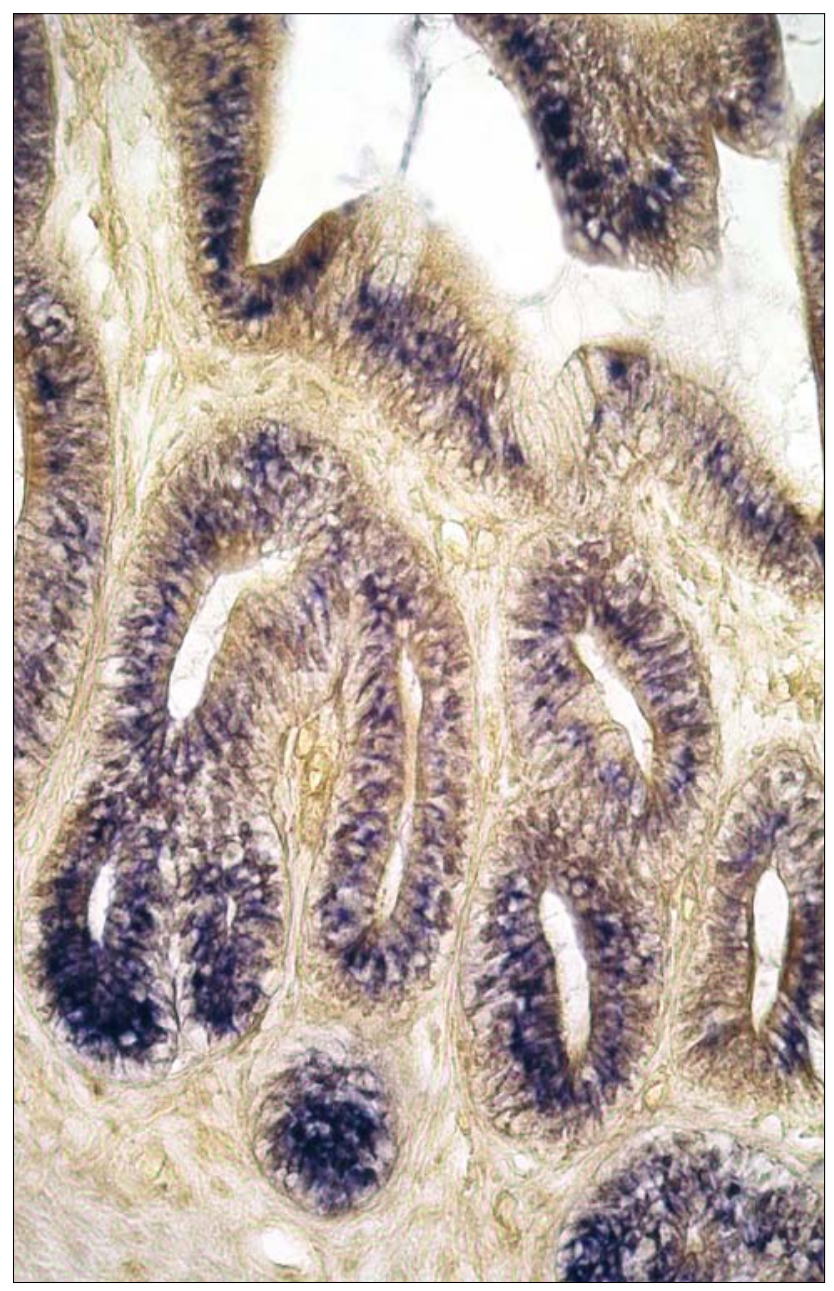

Fig. 2. Double-staining for p63 (brown) and Bax (blue) proteins in duodenum of 18-week-old foetus - detail of the crypt. Magn. 400x. 


\section{RESULTS}

The $6^{\text {th }}-8^{\text {th }}$ week of IUD: We found dispersed PCNA positive cells $(++)$ and rare TUNEL positive cells $(+)$ with no difference in arising villi. All the studied Bcl-2 family proteins were detected: $\mathrm{Bax}$ and $\mathrm{Bcl}-2$ positive cells were more numerous $(++)$ than Bcl-XL (+). p53, p63 and p73 proteins were observed $(++)$, as well as c-myc and $\mathrm{N}$-myc regularly $(++)$ in all samples in this period (c-myc occurrence shown on Fig. 1).

The $10^{\text {th }}-14^{\text {th }}$ week of IUD: On the base of villi with pseudostratified epithelium, there were more numerous PCNA positive cells (++) in comparison to the top of villi $(+)$ covered by single columnar epithelium. The increasing tendency of TUNEL positivity was proved especially on the top of villi. Bcl-2 distribution was similar to that of proliferation. It was present on the base of villi only $(++)$, showing no positivity on their top. The rest of Bcl-2 family proteins, BAX and Bcl-XL did not show significant difference in distribution throughout epithelium. We also found changes in the distribution of p53 family proteins: positivity of $\mathrm{p} 53$ protein rapidly decreased and more positive cells were found in villi epithelium. Both p63 and p73 remained at the same level as in embryonic period with no difference between the villi bottom-top distribution. Both c-myc and $\mathrm{N}$-myc proteins were present in this period and similarly to $\mathrm{p} 63 / \mathrm{p} 73$, they did not show significant differences in their distribution.

The $18^{\text {th }}$ week of IUD: This stage was characterized by strong positivity of the proliferative marker PCNA $(+++)$ in developing Lieberkühn crypts with no proliferation in villi epithelium. Apoptotic (TUNEL positive) cells were observed especially in villi epithelium (++), although there were found single apoptotic stem cells in crypts, too. In the distribution and number of $\mathrm{Bcl}-2$ positive cells, we did not observe any changes in comparison with the previous stage. Bcl-XL and Bax positive cells were more numerous being prevalent (+++) in Lieberkühn crypts (see Fig. 2). None p53 positive cells were found in this period, although p63 (Fig. 2) and p73 positive cells were invariably present both in crypts (++) and villi (++). Both c-myc and $\mathrm{N}$-myc proteins remained only in crypts epithelium $(++)$, no positivity was shown in villi.

\section{CONCLUSIONS AND DISCUSSION}

We demonstrated the occurence of Bcl-2, Bax and $\mathrm{Bcl}-\mathrm{XL}$ proteins from the earliest periods of epithelial differentiation of the duodenal mucosa which was followed by low apoptosis. This finding was also confirmed by other authors ${ }^{4}$. The presence of the Bcl-2 family proteins suggest their probable involvement in interactions controlling apoptosis in embryonic stages of development albeit other important participants in this processes have not been described yet. Our observations of foetal duodenal epithelium are in accordance with studies performed on both animal ${ }^{12}$ and human ${ }^{5}$ tissues in the case of Bcl-2 family proteins, but not to those studying the presence of apoptosis. The presence of apoptotic cells was proved by several authors since the $18^{\text {th }}$ week of development ${ }^{3}$.

The presence of c-myc and N-myc proteins were proved from the earliest stages as well as the other proteins in this study. We did not observe any difference between localization of both proteins described by other research groups, which is dependent on the restriction of c-myc to proliferating stem cells only, and the presence of N-myc in differentiating cells, respectively ${ }^{13}$. In the early foetal period both proteins were localized in both epithelial departments: proliferating (villi bottom) and differentiating (villi top), later on (in the $18^{\text {th }}$ week of intrauterine development), they were limited into the formed Lieberkühn crypts.

Information on the involvement of $\mathrm{p} 63$ in normal cell differentiation of enterocytes in adult intestine is ambiguous $^{14}$ and $^{15}$. However, we proved both p63 and p 73 in epithelium of all samples under study. Although, we cannot estimate the involvement of $\mathrm{p} 63$ and p 73 proteins in the cell cycle/differentiation/apoptosis regulation due to the use of antibodies to their active transactivating isoforms only, our results do suggest possible involvement of this family in prenatal differentiation of the small intestinal epithelium, which may be the starting point for the next study. The presence of $\mathrm{p} 53$ restricted to the earliest stages of development complies with its lower importance during prenatal development ${ }^{9}$ as well as with previous descriptive studies ${ }^{16}$.

\section{ACKNOWLEDGEMENT}

This work was supported by grants MŠMT 15100001.

\section{REFERENCES}

1. Teller IC, Beaulieu JF (2001) Interactions between laminin and epithelial cells in intestinal health and disease. Expert Reviews in Molecular Medicine 8, 1-18.

2. Montgomery RK, Mulberg AE, Grand RJ. (1999) Development of the human gastrointestinal tract: twenty years of progress. Gastroenterology 116, 702-31.

3. Vachon PH, Cardin E, Harnois C, Reed JC, Vezina A. (2000) Early establishment of epithelial apoptosis in the developing human small intestine. Int J Dev Biol 44, 891-898.

4. Matsumoto A, Hashimoto K, Yoshioka T, Otani H. (2002): Occlusion and subsequent re-canalization in early duodenal development of human embryos: integrated organogenesis and histogenesis through a possible epithelial-mesenchymal interaction. Anat Embryol 205, 53-65.

5. Vachon PH, Cardin E, Harnois C, Reed JC, Plourde A, Vezina A. (2001) Early acquisition of bowel segment-specific Bcl-2 homolog expression profiles during development of human ileum and colon. Histology and Histopathology 16, 497-510.

6. Ramachandran A, Madesh M, Subramanian K. (2000) Apoptosis in intestinal epithelium: Its relevance to physiological and pathophysiological conditions. Journal of Gastroenterology and Hepatology 15, 109-120.

7. Chylicki K, Ehinger M, Svedberg H, Gullberg U. (2000) Characterization of the molecular mechanisms for p53-mediated differentiation. Cell Growth Differ 11, 561-71. 
8. Saifudeen Z, Dipp S and El-Dahr SS. (2002) A role for p53 in terminal epithelial cell differentiation. The Journal of Clinical Investigation 109, 1021-1030.

9. Irwin MS and Kaelin WG. (2001) p53 Family Update: p73 and p63 Develop Their Own Identities. Cell Growth \& Differentiation $12,337-349$.

10. Benchimol S. (2001) p53-dependent pathways of apoptosis. Cell death and differentiation $8,1049-1051$.

11. Charron J, Gagnon JF, Cadrin-Girard JF. (2002) Identification of $\mathrm{N}$-myc regulatory regions involved in embryonic expression. Pediatr Res 51, 48-56.

12. Novack DV and Korsmeyer SJ. (1994) Bcl-2 protein expression during murine development. American Journal of Pathology 145, $61-73$.
13. Malynn BA, de Alboran IM, O'Hagan RC, Bronson R, Davidson L, DePinho RA, Alt FW. (2000) N-myc can functionally replace c-myc in murine development, cellular growth, and differentiation. Genes Dev 14, 1390-9.

14. Hall PA, Campbell SJ, O'neill M, Royston DJ, Nylander K, Carey FA and Kernohan NM. (2000) Expression of the p53 homologue p63 and Np63 in normal and neoplastic cells. Carcinogenesis 21, 153-160.

15. Di Como CJ, Urist MJ, Babayan I, Drobnjak M, Hedvat CV, Teruya-Feldstein J, Pohar K, Hoos A, and Cordon-Cardo C. (2002) p63 Expression Profiles in Human Normal and Tumor Tissue. Clinical Cancer Research 8, 494-501.

16. Miosge N, Schneider W, Gotz W, Herken R. (1997) The oncoproteins c-erb-B2, c-fos and the tumour suppressor protein $\mathrm{p} 53$ in human embryos and fetuses. Anat Embryol 195, 345-52. 